\title{
INTERPRETAÇÃO CONSTITUCIONAL NA SOCIEDADE DE PLURALISMO JURÍDICO, ESPAÇOS DE JURIDICIDADE CIDADÃO E OS LIMITES DO DECISIONISMO
}

Bruno Gurgel Bezerra ${ }^{298}$

Recebido em: 09/11/2016

Aprovado em: 10/03/2017

\section{RESUMO}

As normas constitucionais não se confundem com o texto da Constituição. Tal constatação é fruto da superação de uma teoria formal da Constituição, através da qual o Estado readequou-se aos ditames de uma sociedade globalizada e cada vez mais exigente acerca da concretização de suas necessidades. Neste diapasão, evidencia-se uma crítica ao monismo jurídico e, por conseguinte, à visão clássica do Estado Nacional como unidade de poder e de produção do Direito. Todavia, a crítica, em que pese sua importância, merece ser ponderada, sob pena da concessão desenfreada de direitos, ferindo-se a normatividade necessária ao equilíbrio das relações sociais. Dessa forma, o presente ensaio visa apresentar os avanços conquistados pela teoria material da Constituição, ao mesmo tempo em que se preocupa com os limites necessários para que não se tenha um realismo exacerbado no direito.

Palavras-chave: Normas constitucionais. Teoria material da Constituição. Limites.

\section{INTRODUÇÃO}

Diante dos impactos da globalização neoliberal, não é mais possível sequer pensar no Estado Nacional como único ambiente de produção do Direito. Basta olhar para as empresas transnacionais e entidades supranacionais - Organização Mundial do Comércio (OMC), Banco Mundial, Fundo Monetário Internacional (FMI), dentre outras, para perceber a influência de tais entidades nos sistemas jurídicos nacionais. Por sua vez, internamente nos Estados existem

\footnotetext{
${ }^{298}$ Mestrando em Direito pela Universidade Federal do Rio Grande do Norte - UFRN. Especialista em Direito Previdenciário pelo Complexo Jurídico Damásio de Jesus. Bacharel em Direito pela UFRN. Servidor Público da Justiça Federal do Rio Grande do Norte.
} 
também espaços de juridicidade total ou parcialmente autônomos em relação ao Estado (movimentos sociais, entidades religiosas), que interpretam e criam o direito, numa sociedade aberta de intérpretes, trazendo a ideia de que Direito e Política não se resumem ao ambiente estatal. Haveria, por conseguinte, uma repolitização do direito, superando a concepção deste como direito do Estado e da política como política estatal, o que implica pensar na capacidade transformadora do direito para além do que é politicamente legitimado pelo Estado.

Tamanha transformação pode ser reflexo da teoria material da constituição, trazendo efeitos importantes na interpretação. Assim, compreende-se que toda interpretação ocorre em um determinado contexto, que não pode ser desconsiderado. A Constituição e a realidade social sempre se buscam. A realidade fática e a realidade normativa encontram-se em uma relação de reciprocidade, e não é possível separá-las, pois se encontram mutuamente imbricadas.

Assim, o processo interpretativo não é apenas cognitivo, mas fundamentalmente volitivo. No paradigma atual, há a superação de uma concepção tradicional, na qual a interpretação era compreendida apenas como a descoberta do sentido do texto normativo, para outra concepção, na qual se verifica um processo criativo de produção de norma, ou seja, o que se tem é uma atribuição e não uma descoberta de um significado preexistente no enunciado linguístico.

Todavia, malgrado a importância dessa nova postura do direito, o processo criativo possui contornos jurídicos, comumente conhecidos pela imagem do círculo de Hans Kelsen, pela discussão do consenso procedimental de Marcelo Neves, do confronto entre programa normativo e âmbito normativo, os quais resulta na norma de decisão, pelos quais o direito não se torna mero decisionismo ou realismo jurídico americano.

\section{O CONCEITO DE DIREITO NO PARADIGMA DA MODERNIDADE}

Sanção, força, poder coercitivo, um ato do "dever ser", são palavras relacionadas no passado e que ainda continuam a ser enfatizadas no estudo da essência do Direito. Começar um trabalho científico pelo questionamento supra não objetiva o aprofundamento necessário desses temas, porque fugir-se-ia da proposta de um trabalho monográfico, todavia, faz-se presente este tópico, como forma de promover um ponto de partida interessante na estrada teórica a ser percorrida. 
No positivismo, os autores, como Hans Kelsen e John Austin afirmavam o caráter deontológico ${ }^{299}$ do Direito, ou seja, como uma ciência que prescrevesse condutas, ao proibir determinados modos de agir sociais ou determinar a inclinação ao agir socialmente adequado. Dessa forma, o Direito seria o "dever ser", e para sua existência, haveria a necessidade de uma sanção. Então, o buscado pela norma jurídica não era a simples descrição de uma conduta, mas impelir o Estado a conduzir uma reação coercitiva, tornando-se a ciência jurídica uma prescrição.

Tamanho formalismo, expressado na construção "se é A, deve ser B", determinou a veracidade de uma proposição jurídica mediante a noção de poder. O soberano seria uma pessoa ou um grupo cujas ordens costumam ser obedecidas, sem ter a obrigação de também obedecer a outrem. Doutrina aventada pelos doutrinadores supra-referidos, que não pôde sustentar-se, diante de um regime democrático, no qual o povo, na sua totalidade, teria o poder de modificação extrema em face da forma de governo, fazendo, para isso, uma emenda à Constituição.

Apesar de não ter perdido a totalidade de seu conteúdo, tal doutrina fora substituída pelos estudos de Herbert Hart, em seu livro "O conceito do direito". Este autor contrapunha-se ao dito por Austin sobre a autoridade jurídica ser um fato estritamente físico de comando e obediência repetidos. Na verdade, os fundamentos do direito seriam elencados na aceitação ou regra de reconhecimento pela comunidade ${ }^{300}$, ou seja, as convenções sociais que atribuíam o poder a certos grupos ou pessoas a autoridade na elaboração de leis. Todavia, as proposições jurídicas não são verdadeiras apenas em razão da autoridade das pessoas que costumam ser ${ }^{301}$ obedecidas, mas pela aceitação de um sistema de regras que concede a determinados indivíduos ou grupos a prerrogativa de criar leis válidas.

Essas teorias suscitaram diversos debates, essencialmente por estipularem uma aceitação, que no caso concreto seria difícil de se verificar, quando existiria a possibilidade de medo $^{302}$. Como exemplo, muitos oficiais da Alemanha nazista obedeciam às ordens de Hitler, como se fossem leis, porém, obedeceram por medo, dificultando a compreensão do que seria

\footnotetext{
${ }^{299}$ COELHO, Fábio Ulhoa. Para entender Kelsen. São Paulo: Editora Saraiva, 2001, pág. 33

${ }^{300}$ HART, Herbert L. A. O conceito de direito. Pós escrito organizado por Penelope A. Bulloch e Joseph Raz, tradução de Antônio de Oliveira Sette-Câmara. São Paulo: Martins Fontes, 2009, pág.117.

${ }^{301}$ DWORKIN, Ronald. (1997). Taking Rights Seriously. Cambridge: Harvard University Press, pág.15.

302 RAZ, Joseph (1985). “Authority, Law and Morality”. The Monist, vol. 68, no. 3. Illinois: The

Hegeler Institute, pp. 295-324
} 
essa regra de reconhecimento mencionada na teoria de Hart. Sendo assim, exigir-se-ia algo mais além da mera obediência, e em lugares dotados de desumanidade o direito deixariam de existir.

A segunda crítica ao positivismo remete ao teorema da discricionariedade do juiz. Baseando-se na existência de um núcleo e de uma penumbra na lei, os positivistas explicam a razão do poder discricionário como forma de fechar o sistema. Todavia, os próprios positivistas $^{303}$ afirmam que o Direito é construído somente pelas normas, e possíveis lacunas no sistema seriam solucionadas por regras jurídicas, sendo incoerente falar-se em discricionariedade.

Ronald Dworkin ${ }^{304}$ conseguiu decantar seguintes contemplações: 1) o Direito não é um produto humano pronto e acabado, mas submetido a um significado polissêmico; 2) a percepção do que seja o Direito depende, alternativamente, de proposições jurídicas, as quais seriam dados informativos pouco divulgados, fechados numa determinada comunidade, ou, é fruto do conhecimento dos fundamentos de Direito, pouco mais divulgados do que os primeiros.

Diante do exposto, a cada momento histórico, valores nascem dentro da sociedade, incidindo sobre os fatos. Quando ocorre a inserção de cargas axiológicas nos fatos, estes deixam de ser imperceptíveis aos olhos do Direito, constituindo-se nas normas, que regularão a sociedade. Porém, essa valoração de um fato como jurídico não é linear, mas dada uma alternância entre proposições jurídicas e fundamentos de Direito.

Dito de outro modo, as práticas sociais existem, mas não apenas isso, além disso, são moduladas, conforme os valores, interesses, propósitos ou princípios quem levem em conta.

O raciocínio jurídico passa a ser um exercício de interpretação construtiva ${ }^{305}$ e o Direito apresenta-se como importante fundamento para o espectro de prática jurídicas cotidianas e impulso para a melhoria destas. Como toda realidade, a estrutura e as restrições caracterizadoras do argumento jurídico só se manifestam quando identificadas e distinguidas as inúmeras dimensões confrontantes, do valor político, fazendo-se a aplicação integracionista na teoria abstrata do jurídico. Nesse diapasão, existem deficiências interpretativas no positivismo jurídico, já que os juízes sentem uma obrigação de atribuir a decisões passadas um poder

\footnotetext{
${ }^{303}$ BOBBIO, Norberto. Positivismo jurídico - lições de filosofia do direito. Trad. Márcio Pugliese. São Paulo: Ícone, 1995, págs.25-30

${ }^{304}$ DWORKIN, Ronald. O império do direito. Tradução de Jefferson Luiz Camargo. $2^{\mathrm{a}}$ ed. São Paulo: Martins Fontes, 2007, págs. 03 a 55.

305 DWORKIN, Ronald. O império do direito. Trad.Jefferson Luiz Camargo. São Paulo: Martins Fontes, 2007, pág. 120
} 
vinculador, contradizendo o aspecto do positivismo pautado no espaço de discricionariedade do juiz, quando faltar alguma norma.

Parte-se daquela visão formalista, em que o direito é posto ${ }^{306}$ no ordenamento e por isso, apenas conhecido pelo juiz, vinculado à uma atividade declaratória. Chega-se no juiz aceitando o ideal interpretativo da integridade, fazendo com que suas decisões almejem o encontro, dado algum conjunto coerente de princípios sobre os direitos e deveres das pessoas, a interpretação mais adequada à estrutura política e à doutrina jurídica de sua comunidade.

Semelhantemente aos críticos literários (que precisam de uma teoria operacional ou estilo de interpretação) para interpretar um poema por trás do texto, os juízes também precisam de algo como uma teoria da legislação, para fazer valer as leis.

Apesar disso, a obra de Dworkin abre a compreensão de que, posteriormente, as normas constitucionais não seriam o texto da Constituição, mas resultados de um processo de concretização metodologicamente estruturado ${ }^{307}$.

$\mathrm{Na}$ concepção atual, há a superação de uma concepção tradicional, na qual a hermenêutica seria compreendida apenas como a descoberta do sentido do texto normativo ${ }^{308}$, para filiar-se ao entendimento de processo criativo de produção de norma, ou seja, haveria uma atribuição e não uma descoberta de um significado, preexistente no enunciado linguístico. Tudo isso pela constatação de que em qualquer processo de conhecimento, a relação sujeito-objeto é simbiótica, havendo uma atuação recíproca de um sobre o outro.

Verificando-se que nem o positivismo tradicional, bem como, o positivismo "refinado" de Dworkin estiveram a salvos de críticas ${ }^{309}$, por terem colocado o Direito numa perspectiva de mera técnica legislativa, em que a defesa dos fatos evidentes foi um dos preceitos basilares destas Escolas, junto de uma análise interna do Direito, desencadeou-se a separação entre Direito e a sociedade, além das conhecidas lacunas e imperfeições na ciência jurídica.

Neste desiderato, avanços no constitucionalismo tornaram-se caros para um desenvolvimento das relações sociais, reunindo ideias como de integração jurídica (Dworkin), redimensionada na obra de Joaquim José Canotilho ${ }^{310}$. Para este autor, aplica-se, na realidade,

\footnotetext{
${ }^{306}$ GRAU, Eros Roberto. O direito posto e o direito pressuposto. 3. ed. São Paulo: Malheiros, 2000. 209p.

${ }^{307}$ DWORKIN, Ronald. O império do direito. Tradução de Jefferson Luiz Camargo. $2^{\mathrm{a}}$ ed. São Paulo: Martins Fontes, 2007. Págs. 213 a 333.

${ }^{308}$ MAXIMILIANO, Carlos. Hermenêutica e aplicação do Direito. 19a. Edição.

Rio de Janeiro: Forense, 2003, pág.22.

${ }^{309}$ CANOTILHO, José Joaquim Gomes. Direito Constitucional e Teoria da Constituição. 3.ed. (reimpressão). Coimbra: Almedina, 1999, pág.88.

${ }^{310}$ CANOTILHO, José Joaquim Gomes .Direito Constitucional e Teoria da Constituição. 3.ed. (reimpressão). Coimbra: Almedina, 1999, pág.1.109
} 
a Constituição como uma unidade, nos vários campos e áreas específicas, não se pretendendo que as Cartas Magnas recebam as estruturas político-sociais e econômicas, mas sim que as deseje modificá-las, propondo-se uma teoria material da Constituição. Esta modificação se dará quando houver uma realidade social injusta e a necessidade de eliminação dessa desordem a serviço do governo, pois este sempre deseja apenas definir as formas e competências para o exercício do poder, inobservando o problema da legitimação.

Como parâmetro de estudo atual, separa-se o Diploma brasileiro de 1988, dotado de uma realidade em transição, uma vez que conquistas sociais das Constituições de 1934 e de 1946 sofreram um processo de retração, provocado pela ditadura militar (Golpe de 64).

Com a redemocratização, a sociedade depositou diversas expectativas ${ }^{311}$, resultantes tanto de conquistas passadas, que se tornaram represadas, quanto de novos anseios, e este acúmulo exacerbado de justos desejos não poderiam ser resolvidos pelos tradicionais métodos de composição jurídica de conflitos, como a subsunção, o espaço discricionário do juiz, análise interna do Direito, o "tudo ou nada" etc.

Todavia, em que pese o nível de exigências sociais ter tido um incremento, o Estado brasileiro necessita de um tempo ${ }^{312}$ para o restabelecimento da ordem natural dos direitos; por isso, a noção de identidade entre constituição e indivíduos ou a Magna Carta como espaço de cidadania possui caráter progressivo, uma vez que durante os tempos de poder arbitrário não existia unidade política (o poder político era exercido por uma classe, por vezes, minoritária), bem assim, suas tarefas estavam desordenadas.

Todavia, em que pese a contribuição para a teoria social da Constituição, Canotilho fundamentou sua tese na historicidade, quando diluir $^{313}$ processos de emancipação políticojurídica na história, pode ser perigoso, considerando que ela poderia ser contada por aqueles grupos subjetivamente interessados. Ademais, o autor defende a sua estrutura com base na imposição de tarefas e programas que os poderes públicos devem concretizar, elucidando um Estado intervencionista, em que se considera o texto constitucional, nesse desiderato, como um substituto do processo de decisão política, ao ser promovido tamanho dirigismo estatal.

Desse modo, não basta conhecer a Super Lei, mas sim aprofundar-se numa tarefa investigativa além da aparência, somando-se todos recursos anímicos do Constituinte,

\footnotetext{
311 BONAVIDES, Paulo. Curso de Direito Constitucional. 16.ed. São Paulo: Malheiros, 2005, pág.127

312 CANOTILHO, José Joaquim Gomes .Direito Constitucional e Teoria da Constituição. 3.ed. (reimpressão). Coimbra: Almedina, 1999, pág.1.112

${ }^{313}$ Ibidem, pág.1.144
} 
materializados no documento formal, ou seja, trazer à tona toda carga de experiências vivenciadas pelos nossos antepassados.

Noutras palavras, complementa-se a doutrina de Canotilho com a concepção de reconhecer o mundo dentro de si, mas também o "eu" inserido na Constituição, pois o simples fato da historicidade constitucional poderia ser apenas uma teoria, e considerando-se isso, o Estado, quando teorizado, poderia ter servido para a conformação do poder político hegemônico, sem um diálogo efetivo com as demais Ciências Humanas ${ }^{314}$.

Embora a teoria psicológica traga aparentemente o subjetivismo e aspectos individuais,

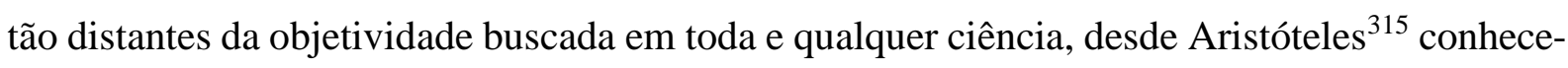
se a existência de uma disposição de caráter, relacionada com a escolha de ações e paixões, referente a uma mediania, determinada por um princípio racional próprio do homem dotado de sabedoria prática. Desse modo, existiria um meio-termo entre dois vícios, um por excesso e outro por falta, pois nos vícios ou há falta ou há excesso daquilo que é conveniente no que concerne às ações e às paixões, ao passo que a virtude encontra e escolhe o meio-termo.

O filósofo grego afirmava que existia um ponto de intersecção entre os sentimentos, denominado de virtude, retirando o conflito entre os sentimentos. Dessa forma, nos Jogos Olímpicos, não são os homens mais belos e mais fortes que conquistariam a coroa, mas aqueles que competiam (pois seria no meio destes que surgiriam os vencedores), e, do mesmo modo, as coisas nobres e boas da vida só são conquistadas pelos que agem retamente, com virtude.

Rompe-se com a concepção tradicional de segurança jurídica (nos termos kelsenianos), em que poderia haver uma única resposta para cada problema jurídico e um desenho institucional perene e, por isso mesmo, "verdadeiro"316. Ademais, em outro giro, franqueia a existência do direito com sociedades plurais e altamente complexas. A estabilização temporária de desenhos institucionais e modelos hermenêuticos permite que os indivíduos e grupos alcancem compromissos temporários, contingentes, os quais serão superados por novos conflitos, novas reivindicações de grupos sociais, novas demandas individuais.

\footnotetext{
314 BONAVIDES, Paulo. Curso de Direito Constitucional. págs. 108 a 130

315 ARISTÓTELES. Ética a Nicômaco. Martin Claret: São Paulo, 2003.

316 ÁVILA, Humberto. Teoria dos princípios: da definição à aplicação dos princípios jurídicos. 4.ed. rev. 2.tir. São Paulo: Malheiros, 2005, pág.45
} 


\section{HERMENÊUTICA CONSTITUCIONAL: INSTRUMENTO IMPLEMENTAÇÃO DE UMA NOVA DOGMÁTICA JURÍDICA ${ }^{317}$}

PARA

A repercussão de uma teoria nova do Direito possui consequências diretas na atividade interpretativa. O fenômeno jurídico transforma-se conforme os anos. Para tanto, observa-se que a epistemologia de qualquer ciência possui, fundamentalmente, produção teórica múltipla, coexistindo diversos discursos num espaço sem fronteiras para o conhecimento. Neste ínterim, a epistemologia e hermenêutica jurídicas da atualidade estão consagrados num ambiente dialético e multidisciplinar, fulcrado em projetos ético-políticos dos operadores jurídicos.

O problema reside na medida dessa abertura, propiciando dois ambientes diversos: um para as teorias interpretativistas; em oposição, outro para teorias não-interpretativistas.

Como características principais, a teoria interpretativista ${ }^{318}$ possui epistemologia descritivista, de base positivista, pressupondo a neutralidade dos operadores jurídicas. Entre as ideias principais, urge destacar a da moldura jurídica. Hans Kelsen afirmou que a ciência jurídica (e somente ela) construiria um âmbito de conformação semântico das normas jurídicas, em que a partir dele o intérprete "escolheria" as teses interpretativas forjadas dentro de tal moldura jurídica. O Direito é mais antigo que as outras disciplinas, não só no Brasil, e este princípio de antiguidade fez com que estivesse diretamente ligado ao poder político do País, no século XIX, podendo se arrogar a condição de "disciplina-rainha" das Ciências Humanas, condição que era até meados de 1980 cunhada à Sociologia. O Direito só considerava as Ciências Humanas na medida em que traziam algum elemento para reflexão propriamente jurídica, sem haver um diálogo efetivo. Quando os teóricos do Direito eram chamados para um consórcio interdisciplinar, eles vinham mais como consultores, para dizer qual o ponto de vista do Direito, que propriamente visando construir um diálogo, como ocorreu com outras disciplinas das Ciências Humanas. No caso dos teóricos do Direito, mantém-se a perspectiva da Sociologia, da Antropologia, da História e da Economia como merecedoras de importância apenas quando tangem a reflexão propriamente jurídica.

Apesar do esforço em manter a Teoria Pura, Kelsen observou, em escritos posteriores, que não haveria tal moldura jurídica, uma vez que o próprio Poder Constituinte deveria ser

\footnotetext{
317 Este texto é baseado no fichamento de GOMES CANOTILHO, JJ. Direito Constitucional e Teoria da Constituição, Parte IV, Cap. 04. Interpretação, aplicação e Concretização do Direito Constitucional. $7^{\mathrm{a}} \mathrm{ed}$.

${ }^{318}$ Ibidem, pág.1.125.
} 
atualizado no decorrer dos tempos, não ficando adstrito àquele momento de Revolução, tendo a constatação sido denominada de "giro decisionista de Kelsen".

Por isso, as teorias não interpretativistas tomaram espaço, defendendo que ao juiz seria lícita e necessária a invocação e aplicação, na leitura/construção da realidade constitucional, valores substantivos (liberdade e justiça), fulcrado no Projeto da Constituição apreciado pela totalidade dos cidadãos, sem descurar dos demais valores constitucionais, em que pese a importância da teoria interpretativista democrática ${ }^{319}$.

Por isso, é de suma importância entender os limites e possibilidades da tutela jurisdicional sob o novo paradigma constitucional, para não se recair num decisionismo extremo que atinja a normatividade necessária à formalização de decisões racionais e científicas no Direito.

Apesar disso, é a teoria não interpretativista a mais adequada aos preceitos de uma sociedade em constante dialética e que prima pela materialidade dos valores constitucionais, forcejando a inserção da ética nos projetos sociais elaborados no pacto fundador. Aplica-se, na realidade, a Constituição como uma unidade, nos vários campos e áreas específicas, caracterizando o movimento atual das constituições sociais, programáticas ou econômicas. Muito mais do que respeito às limitações materiais ou formais da Constituição, o legislador deverá se conformar, ao elaborar atos normativos, com os ideais dos constituintes (os quais são uma série de diretrizes constitucionais ou Constituição Dirigente). Racionaliza-se a política, face à constatação de que a Constituição não é só uma garantia do existente, mas também um programa para o futuro (mudança da realidade pelo Direito), sistematizando, assim, além do ordenamento jurídico, o Direito e a sociedade, pela interdependência entre Estado e sociedade.

Por conta disso, a consciência histórica e os pré-conceitos, denominados de "consciência hermenêutica" 320 , são elementos que trazem a compreensão e o conhecimento do objeto da interpretação. Em outras palavras, as leis históricas e o determinismo social, tão caros à doutrina Marxista, servem como vetores interpretativos do texto constitucional, determinando, por conseguinte, as finalidades das normas-base envolvidas no processo histórico e de précompreensões, bem como orientariam os modelos de resolução de eventual conflito entre segurança jurídica e a atualização adequada das regras de convívio social.

\footnotetext{
${ }^{319}$ Ibidem, pág.1.26.

${ }^{320}$ DO VALLE, Vanice Regina Lírio. Delegificação, legitimidade e segurança jurídica: a hermenêutica constitucional como alternativa de harmonização. A \& C : Revista de Direito Administrativo e Constitucional, Belo Horizonte, v. 4, n. 18, out. 2004 Pág.155.
} 
O locus de tal programa de ação na Constituição de 1988 seriam os objetivos fundamentais, uma vez que formulam a política do Estado (ao identificarem o regime constitucional), individualizam o Estado (dizem respeito ao tipo de Estado, regime político, valores inspiradores do ordenamento, fins do Estado), por fim, definem e delimitam a identidade da Constituição perante seus cidadãos.

Tendo em vista o mencionado, são os objetivos fundamentais a síntese jurídico-política da Constituição, tornando-se cláusulas transformadoras, ao explicitarem o contraste entre a realidade social injusta e a necessidade de eliminá-la, num movimento progressivo e dinâmico, sempre inacabado.

Face ao exposto, cada período possui a Carta que necessita, sendo este sentimento defendido na doutrina de Canotilho ${ }^{321}$, o qual denominou a historicidade como elemento teórico de suma importância, no entendimento da "Constituição constitucionalmente adequada". Afinal, o fator historicidade influencia estruturas e arquiteturas estatais com a própria identidade nacional. Por consequência, o Estado, como elaborador da Super Lei, deverá, ao formular os enunciados constitucionais, orientar-se pela ação deflagrada a partir do povo no processo constituinte, porque em caso de não orientação conforme a luta constitucionalista específica em cada período, o Diploma Cidadão não guardará com o povo a quem ele se destina - e a quem se atribui sua gênese - qualquer identidade.

Como parâmetro de estudo atual, separa-se o Diploma de 88, dotado de uma realidade em transição, uma vez que conquistas sociais das Constituições de 1934 e 1946 sofreram um processo de retração, provocado pela ditadura militar.

Com a redemocratização, a sociedade depositou diversas expectativas, resultantes tanto de conquistas passadas, que se tornaram represadas, quanto de novos anseios, e este acúmulo exacerbado de justos desejos não poderiam ser resolvidos pelas tradicionais regras de composição de conflitos, como a subsunção, o espaço discricionário do juiz, a análise interna do Direito (regras do "tudo ou nada").

$\mathrm{Na}$ realidade, a atividade interpretativa dever $\mathrm{te}^{322} \mathrm{r}$ : 1)pressupostos subjetivos, dado que o intérprete desempenha um papel criador (pré-compreensão) na tarefa de obtenção do sentido do texto constitucional; 2) os pressupostos objetivos, isto é, o contexto, atuando o

${ }^{321}$ CANOTILHO, José Joaquim Gomes. Direito Constitucional e Teoria da Constituição. 3 ed. (reimpressão). Coimbra: Almedina, 1999.págs. 1.123 a 1.155.

322322 DO VALLE, Vanice Regina Lírio. Delegificação, legitimidade e segurança jurídica: a hermenêutica constitucional como alternativa de harmonização. A \& C : Revista de Direito Administrativo e Constitucional, Belo Horizonte, v. 4, n. 18, out. 2004 Pág.155 
intérprete como operador de mediações entre o texto e a situação em que se aplica; 3)relação entre texto e contexto, com a mediação criadora do intérprete, transformando a interpretação em movimento de ir e vir (círculo hermenêutico).

Tudo isso veio com o estudo do método concretista, o qual compreenderia um conjunto de componentes semânticos dos textos normativos, como também componentes fáticos. Desse modo, ao mesmo tempo que se vincula aos enunciados, tem-se a percepção da necessidade de complementariedade, feita a partir da realidade, um construtivismo complementar do programa normativo com o campo normativo ${ }^{323}$.

Seriam as características do método concretista: 1) vinculação da interpretação à resolução de problemas concretos e práticos; 2)preocupação com a estrutura da norma conjuntamente com a do texto normativo; 3 ) hermenêutica da norma em toda sua estrutura, e não hermenêutica da identidade texto-norma; 4) o texto do preceito é apenas a ponta do iceberg normativo, que abrange também o domínio ou setor normativo (programa) - realidade social ${ }^{324}$.

Por conta da hipercomplexidade da sociedade, o esforço dos juristas estará em reconhecer e , por conseguinte, solucionar: a) as práticas que desrespeitam os próprios procedimentos ou os direitos fundamentais, caracterizadas como ilícitas ou inválidas; b) a emergência, no mundo da vida e na esfera pública, de valores que objetivam, implicitamente, a neutralização do Estado Democrático de Direito (fala-se implicitamente em razão de, em que pese a vontade de suprimir o Estado Democrático de Direito, tais valores respeitam os procedimentos e direitos fundamentais daquele).

\section{LIMITES DA INTEPRETAÇÃO DIANTE DA SOCIEDADE PLURALISTA}

A estrutura da norma constitucional apresenta-se determinada pelo programa normativo e pelo âmbito normativo, e a conexão entre ambos irá resultar na norma de decisão. O primeiro está associado à expressão literal, já o segundo é entendido como a realidade circundante ${ }^{325}$.

\footnotetext{
${ }^{323}$ Ibidem, pág.155.

324 Ibidem. Pág.155

${ }^{325}$ CANOTILHO, José Joaquim Gomes. Direito Constitucional e Teoria da Constituição. 3.ed. (reimpressão). Coimbra: Almedina, 1999, pág.1.140
} 
O texto constitui o ponto de partida para a formação das significações e, ao mesmo tempo, para a referência aos entes significados. As normas resultam da interpretação dos textos e interpretar seria atribuir valores aos símbolos.

Esta abertura da norma constitucional possui limites, começando pelo programa normativo. Este seria o resultado da interpretação do texto normativo, ou seja, o que é expresso pelo teor literal, bem como todos os recursos interpretativos auxiliares, sendo formado a partir dos dados da linguagem. Assemelha-se ao círculo de Kelsen, em que a doutrina faria um estudo, trazendo possíveis interpretações daquela norma. Posteriormente, o legislador ou intérprete escolheria a interpretação contextualmente possível e adequada.

Em segundo patamar, o âmbito normativo também faz uma seleção de elementos estruturais extraídos da realidade social, a partir de uma perspectiva valorativa do programa normativo. O âmbito normativo é formado com a influência da perspectiva valorativa do programa normativo, a partir do âmbito material ou do âmbito do caso. O âmbito material designa a totalidade das hipóteses sobre a questão de fato inicialmente introduzidas de forma associativa ara fins de narrativa do caso. Além disso, o âmbito do caso representa um recorte deste âmbito material.

Muller ensina: "com a distinção entre âmbito material e âmbito normativo fica descartada a força normativa do fático como usurpação da eficácia normativa por parte de meros fatos"326.

Saber até que ponto a interpretação e a aplicação do direito podem apoiar-se na facticidade social e em resultados da pesquisa sociológica - sem errar o alvo da normatividade do direito - deve ser visto como um problema de metodologia jurídica. "Aspectos da realidade social só podem entrar na dogmática e metódica jurídicas no interesse da normatividade jurídica, a serviço da racionalidade especificamente jurídica em vinculação da norma"327.

O desafio da Dogmática Jurídica de estilo hermenêutico consistiria nessa dualidade ${ }^{328}$ : Aparelhamento do sistema jurídico capaz de ampliar as incertezas de uma sociedade, pressionada pelas transformações rápidas, pelo crescimento das possibilidades de ação etc, ao mesmo tempo em que, este aparelhamento tenha a capacidade também de impedir que todas as consequências venham a ser legitimadas, orientando-se o sistema jurídico por essas consequências, mas sem perder o controle.

\footnotetext{
${ }^{326}$ MULLER, Friedrich. O novo paradigma do direito: introdução à teoria e metódica estruturantes. P.30

${ }^{327}$ MULLER, Friedrich. Teoria estruturante do direito. P.58

${ }^{328}$ BARROSO, Luís Roberto. O controle de constitucionalidade no direito brasileiro. 2.ed. rev. e atual. São Paulo: Saraiva, 2006, pág.67
} 
O segundo limite seria o limite objetivo da letra do Texto Constitucional. Não há palavra imprecisa e vaga que não possua um núcleo de significação essencial, um mínimo de densificação semântica, a moldura jurídica.

Por fim, deve-se ter em mente sempre a proporcionalidade, como forma de equalizar a legitimidade dos grupos de pressão, a partir da legitimidade dos valores defendidos e não da dimensão populacional dos seus integrantes, tudo em razão de que, numa sociedade democrática, necessariamente pluralista, muitas vezes são minorias que têm que ser defendidas contra a maioria.

Dessa forma, em que pese o debate sobre as diversas justificativas possíveis para a construção da norma de decisão ser uma constante no panorama moderno do direito, em algum momento deve-se chegar a uma decisão precisa (solução mais adequada ao caso concreto). $\mathrm{O}$ direito intrinsecamente indeterminado (conceitos abertos, cláusulas indeterminadas) deve ter o seu momento de autoridade, como forma de "conseguir regular a sociedade" (RODRIGUEZ, José Rodrigo. Zonas de autarquia nas decisões jurisdicionais: Estado de Direito, indeterminação e democracia. In: Estado de Direito e o desafio do desenvolvimento, p.300).

\section{CONSIDERAÇÕES FINAIS}

O presente artigo partiu da compreensão atual do pluralismo jurídico, como resultado da globalização e componente de transformação da teoria formal da constituição, implicando numa nova interpretação. Liga-se, por conseguinte, às dimensões da cidadania, enquanto a) garantias de direitos; b) participação; c) aspectos de identidade/pertencimento.

Assim, tentou-se demonstrar, com a implementação da teoria material da constituição, que a significação da Constituição não é dada de antemão, mas dependente do contexto no qual é concretizada. O sentimento constitucional presente em cada momento vivido passa a permear a realização da Constituição, e a natureza dinâmica da Constituição, como organismo vivo que é, permite que ela possa acompanhar a evolução das circunstâncias políticas, sociais e econômicas.

O grande avanço na compreensão constitucional, todavia, apresenta limites, sob pena de tornar o direito um realismo sem fronteiras, trazendo insegurança e total anarquia. 


\section{REFERÊNCIAS}

ARISTÓTELES. Ética a Nicômaco. Martin Claret: São Paulo, 2003.

BONAVIDES, Paulo. Curso de Direito Constitucional. 16.ed. São Paulo: Malheiros, 2005

BARROSO, Luís Roberto. O controle de constitucionalidade no direito brasileiro. 2.ed. rev. e atual. São Paulo: Saraiva, 2006

BOBBIO, Norberto. Positivismo jurídico - lições de filosofia do direito. Trad. Márcio Pugliese. São Paulo: Ícone, 1995.

CANOTILHO, José Joaquim Gomes. Direito Constitucional e Teoria da Constituição. 3 ed. (reimpressão). Coimbra: Almedina, 1999

DWORKIN, Ronald. O império do direito. Tradução de Jefferson Luiz Camargo. $2^{\mathrm{a}}$ ed. São Paulo: Martins Fontes, 2007.

DO VALLE, Vanice Regina Lírio. Delegificação, legitimidade e segurança jurídica: a hermenêutica constitucional como alternativa de harmonização. A \& C : Revista de Direito Administrativo e Constitucional, Belo Horizonte, v. 4, n. 18, out. 2004

GARCIA, Maria. O cidadão, intérprete da Constituição. Revista de Direito Constitucional e Internacional - Cadernos de Direito Constitucional e Ciência Política - Ano 12 - JulhoSetembro-48. São Paulo: Revista dos Tribunais, 2004. p.102-113

GRAU, Eros Roberto. O direito posto e o direito pressuposto. 3. ed. São Paulo: Malheiros.

HART, Herbert L. A. O conceito de direito. Pós escrito organizado por Penelope A. Bulloch e Joseph Raz, tradução de Antônio de Oliveira Sette-Câmara. São Paulo: Martins Fontes, 2009

LEITE, Marcelo Santos. A influência dos grupos de pressão na interpretação constitucional. Revista de Direito Constitucional e Internacional - Cadernos de Direito Constitucional e Ciência Política - Ano 12 - Julho-Setembro-48. São Paulo: Revista dos Tribunais, 2004. p.187-211

MULLER, Friedrich. O novo paradigma do direito: introdução à teoria e metódica estruturantes. São Paulo: Revista dos Tribunais, 2007. 
MULLER, Friedrich. Teoria estruturante do direito. 2. ed. São Paulo: Revista do Tribunais, 2009.

MAXIMILIANO, Carlos. Hermenêutica e aplicação do Direito. 19a. Edição.

Rio de Janeiro: Forense, 2003.

NEVES, Marcelo. Entre Têmis e Leviatã: Uma relação difícil. São Paulo: Martins Fontes, 2006.

RODRIGUEZ, José Rodrigo. Zonas de autarquia nas decisões jurisdicionais: Estado de Direito, indeterminação e democracia. In: Estado de Direito e o desafio do

desenvolvimento. São Paulo: Saraiva, 2011.

RAZ, Joseph (1985). “Authority, Law and Morality”. The Monist, vol. 68, no. 3. Illinois: The Hegeler Institute.

\title{
CONSTITUTIONAL INTERPRETATION IN A LEGAL-PLURALISM SOCIETY, CITIZEN-FRIENDLY JURIDICITY SPACES AND LIMITS FOR DECISION MAKING
}

\begin{abstract}
Constitutional rules are not confused with the text of the Constitution. This finding is the result of overcoming a formal theory of the Constitution, whereby the State readequou up to the dictates of a globalized society and increasingly demanding about the realization of their needs. In this vein, evidence-a critique of legal monism and, therefore, the classical view of the nation state as the unit of power and production of law. However, criticism, despite its importance, deserves to be considered, under penalty of unrestrained granting of rights, injuring themselves needed to balance the normativity of social relations. Thus, this essay aims to present the advances made by the material theory of the Constitution, while that is concerned with necessary so as not to have an exaggerated realism in the right limits.
\end{abstract}

Keywords: Constitutional rules. Material theory of the Constitution. Limits. 